\title{
New Functions of Polyaniline
}

\author{
Hongbo Gu, ${ }^{1, *}$ Hongyuan Zhang, ${ }^{1}$ Chong Gao, ${ }^{1}$ Chaobo Liang, ${ }^{2,3}$ Junwei Gu, ${ }^{2,3 *}$ and Zhanhu Guo ${ }^{4 *}$
}

Owing to the excellent electrical conductivity and unique chemical structures, conducting polymer polyaniline (PANI) has been widely utilized in many application fields. In this review, the state-of-art current research status on the recent developed new functions of PANI in the applications including environmental remediation, giant magnetoresistance (GMR) sensors, coupling agents, metamaterials, and energy storage devices have been critically reviewed. This knowledge will further broaden the application scope of PANI and provide the basis for the researchers to seek the new application of PANI in the future.

Keywords: Polyaniline; New Functions; Environmental Remediation; Coupling Agents; Giant Magnetoresistance Sensors; Metamaterials; Energy Storage

Received 23 August 2018, Accepted 29 September 2018

DOI: $10.30919 / \mathrm{esmm} 5 \mathrm{f} 108$

\section{Introduction}

Since the first discovery of electrical conduction in polymers in 1977 with the report that describes the polyacetylene doped with halogens, ${ }^{1}$ the conducting polymers have stepped into a new era. ${ }^{2}$ Conducting polymers, such as polyacetylene (PA), polyaniline (PANI), polypyrrole (PPy), polythiophenes (PTs), and poly(DNTD), have gained more attentions in the last few decades. ${ }^{3}$ Among various conducting polymers, PANI with the advantages of easy synthesis, low cost of monomers, good chemical stability, simple protonation/deprotonation process, tunable electrical conductivity and high pseudocapacitance values has become most often studied conducting polymers over the past years ${ }^{4-6}$ with the applications in the supercapacitors, ${ }^{7-9}$ electrochromic materials, ${ }^{10}$ hydrogen photoproduction, ${ }^{11}$ gas sensors, ${ }^{12}$ and environmental remediation. ${ }^{13-15}$ The nitrogen atom in PANI polymer backbone participates in the $\pi$ band formation and electrical conduction. ${ }^{16}$ PANI is composed of

\footnotetext{
'Shanghai Key Lab of Chemical Assessment and Sustainability, Department of Chemistry, Tongji University, Shanghai, 200092, China

${ }^{2} \mathrm{MOE}$ Key Laboratory of Material Physics and Chemistry under Extraordinary Conditions, Shaanxi Key Laboratory of Macromolecular Science and Technology, Department of Applied Chemistry, School of Science, Northwestern Polytechnical University, Xi' an, Shaanxi, 710072, P.R. China

${ }^{3}$ Institute of Intelligence Material and Structure, Institute of Unmanned Systems, Northwestern Polytechnical University, Xi'an, Shaanxi, 710072, P.R. China

${ }^{4}$ Integrated Composites Lab (ICL), Department of Chemical \& Biomolecular Engineering University of Tennessee, Knoxville, Tennessee, 37966, USA

*E-mail: hongbogu2014@tongji.edu.cn; gjw@nwpu.edu.cn; zguo10@utk.edu
}

amine groups and imine groups repeating units and possesses three oxidation states, ${ }^{17}$ which termed as "leucoemeraldine base" (LEB), "emeraldine base" (EB) and "pernigraniline base" (PB) forms, accordingly. ${ }^{18}$ Normally, LEB and PB forms are intrinsically insulating, even after doping; only EB form is able to be electrically conductive upon doping/protonation process and can be changed to the emeraldine salt (ES) form. Since these three states of PANI exhibit different colors, in which the LEB form is colorless or light yellow, the EB form - blue, the ES form - green (a symbol of electrical conduction of PANI), and the PB form - violet or black, ${ }^{19}$ This makes PANI to act as the electrochromic matters for the smart windows and displays. ${ }^{10,19}$

Recently, even some comprehensive reviews are focused on the preparation, processing and applications of PANI, ${ }^{20}$ negative permittivity of PANI nanocomposites, ${ }^{21}$ PANI based biosensors, ${ }^{22}$ PANI membrane for separation and purification of gas, liquids, and electrolyte solutions, ${ }^{23}$ PANI nanofibers ${ }^{24}$ and giant magnetoresistance property in PANI and its nanocomposites. ${ }^{16}$ In contrast, this work summarizes the recent discoveries about the new application fields of PANI nanostructures which are not involved in the previous report including environmental remediation, giant magnetoresistance (GMR) sensors, coupling agent for epoxy and nanofillers, metamaterials, and energy storage in details.

\section{New Functions of Polyaniline}

\subsection{Environmental Remediation}

Owing to the rapid economic and industrial development including metal plating facilities, tanneries, mining operations, batteries, paper industries, fertilizer industries, and pesticides, etc., ${ }^{25}$ heavy metal pollution is being a serious environmental problem faced by humans. ${ }^{26} \mathrm{Cr}(\mathrm{VI})$ is a commonly identified heavy metal contaminant due to its high toxicity and mobility. ${ }^{27}$ The US Environmental Protection Agency (EPA) allows a maximum contaminant level 


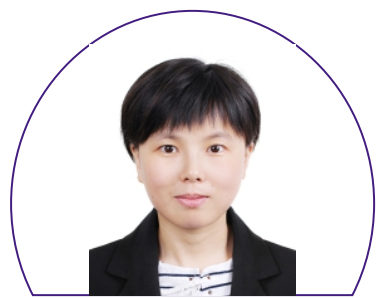

Hongbo Gu

Hongbo Gu, received her Ph.D. degree of Chemical Engineering and Technology at Harbin Institute of Technology (HIT) in Jan. 2014, China. During her graduate study, she worked as a joint Chemical Engineering PhD student with Prof. Zhanhu Guo at Lamar University sponsored by China Scholarship Council (CSC). Currently, she is an Associate Professor at the School of Chemical Science and Engineering, Tongji University (TJU) in China. Her research interests focus on the giant magnetoresistance (GMR) sensors, multifunctional polymer nanocomposites especially the magnetic and conductive materials for the environmental remediation and electronic devices.

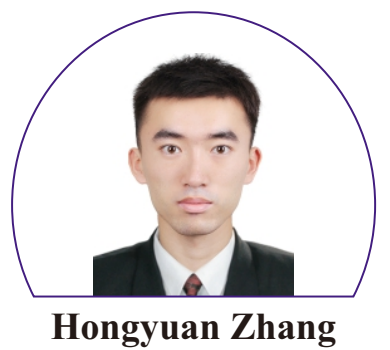

Hongyuan Zhang, received his Bachelor's degree at Tongji University (TJU) in July 2016, China. Currently, he is a master student with major of Chemical Engineering and Technology at the School of Chemical Science and Engineering, TJU. His research concentrates on the design, preparation and applications of multifunctional epoxy nanocomposites especially the strengthened and electrical conducting epoxy nanocomposites.

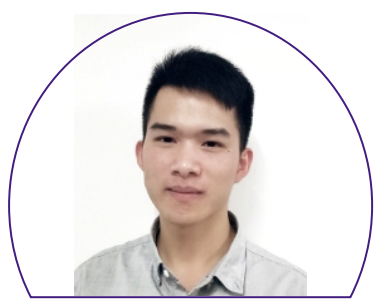

Chong Gao

Chong Gao, currently, he is a master candidate majoring in Chemistry at the School of Chemical Science and Engineering, Tongji University (TJU). His research interest mainly focuses on the preparation and application of multifunctional polymer nanocomposites and conducting polymer nanocomposites.

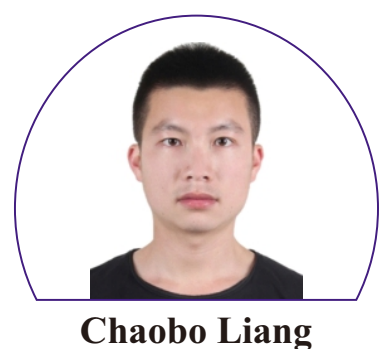

Chaobo Liang, obtained his Bachelor's degree from Northwestern Polytechnical University (NPU) in 2015, China. Currently, he is a PhD candidate majoring in Material Science at NPU. His research interests focus on the microstructure design, performance control and mechanism exploration of thermally conductive and electromagnetic shielding polymeric composites.

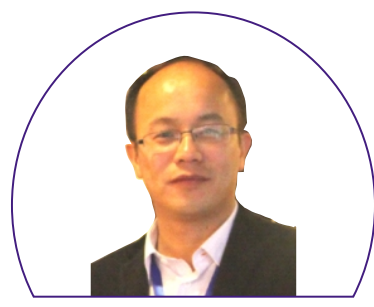

Dr. Junwei Gu

Dr. Junwei Gu, is a full Professor and Leader of the Functional Polymeric Composites Groups in the Department of Applied Chemistry at the Northwestern Polytechnical University (NPU). He received his Ph.D. degree of Material Science from NPU in 2010. His current research focuses on the thermally conductive polymeric composites, fibres/polymeric matrix wavetransparent composite materials, electromagnetic shielding polymeric composites, ablation-resistance polymeric composites, surface/interface modification, mechanisms and simulation.

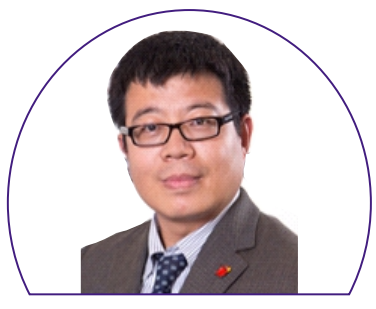

Zhanhu Guo

Zhanhu Guo, currently an Associate Professor of Chemical Engineering at University of Tennessee, obtained a Chemical Engineering Ph.D. degree from Louisiana State University (2005) and received three-year (2005-2008) postdoctoral training in Mechanical and Aerospace Engineering Department in University of California Los Angeles. Dr. Guo, the Chair of the Composite Division of American Institute of Chemical Engineers (AIChE, 2010-2011), directs the Integrated Composites Laboratory (ICL) with more than 20 members and. His current research focuses on fundamental science behind multifunctional nanocomposites for energy harvesting, electronic devices, environmental remediation, anti-corrosion, fire-retardancy, and electromagnetic radiation shielding/absorption applications. 
(MCL) for total chromium to be $100 \mathrm{~g} \mathrm{~L}^{-1}$ in accordance with the national primary drinking water regulations. ${ }^{28}$

In the last decade, the heavy metal removal through PANI systems has attracted much more interests because of their reversibility and high heavy metal removal efficiency. ${ }^{29}$ PANI with different morphologies and PANI nanocomposites have been synthesized to be used for the heavy metal removal from the waste water system. ${ }^{30,31}$ Wang et al. ${ }^{32}$ used PANI to remove $\mathrm{Hg}$ (II) from water solution and proposed that the $\mathrm{Hg}$ (II) adsorption on PANI was due to the complexation between $\mathrm{Hg}$ (II) and nitrogen binding sites on the polymer backbone of PANI. However, this proposed mechanism wasn't been verified in this work. Kumar et al. ${ }^{33}$ prepared the PANI on the surface of jute fiber with 1,4-phenylenediamine as chain terminating reagent, which could effectively remove $\mathrm{Cr}(\mathrm{VI})$ from wastewater. Zhang et al. ${ }^{34}$ synthesized PANI nanofibers doped with sulfuric acid without adding of seed fibers, oligomers, and other templates, which showed a good $\mathrm{Cr}(\mathrm{VI})$ removal performance with a maximum uptake around $95.79 \mathrm{mg} \mathrm{g}^{-1}$. Olad et al. ${ }^{35}$ studied the $\mathrm{Cr}$ (VI) removal efficiency and kinetics on the PANI film and powder at different oxidation states., The PANI film was relatively difficult to prepare in a large amount in a short time compared with powder form. In addition, PANI film with a smaller specific surface area might restrict the penetration of $\mathrm{Cr}(\mathrm{VI})$ into the interior of PANI film, leading to a relatively lower ability for $\mathrm{Cr}(\mathrm{VI}){ }^{36}$ By contrast, PANI powders with a rough surface were a good candidate for highly efficient $\mathrm{Cr}(\mathrm{VI})$ removal because of their large specific surface area, and ease of bulk production. ${ }^{37}$ Guo et al.$^{38}$ fabricated the bulk-quantity 1D PANI nanowire/tubes with the rough surface by a simple chemical oxidation method, which could not only rapidly and effectively remove $\mathrm{Cr}(\mathrm{VI})$ from aqueous solution in one step through reducing $\mathrm{Cr}(\mathrm{VI})$ to $\mathrm{Cr}(\mathrm{III})$ as well as simultaneously adsorbing the reduced $\mathrm{Cr}(\mathrm{III})$, but also be easily regenerated for reuse. Normally, the ES form of PANI could be oxidized to the PB form after treated with $\mathrm{Cr}(\mathrm{VI})$ and the PB form could be reduced by directly treated with acidic aqueous solution as proved by MacDiarmid et al. ${ }^{17}$ Fig. 1 illustrates the conversion between ES form of PANI and PB form of PANI. This could help PANI be regenerated after treated with $\mathrm{Cr}(\mathrm{VI})$ and reused. However, it is still a challenge to sustainably recycle the PANI powders after $\mathrm{Cr}(\mathrm{VI})$ treatment and the interactions between PANI and $\mathrm{Cr}(\mathrm{VI})$ are still unknown.

More recently, a new method to recycle the PANI adsorbents by introduction of the magnetic nanoparticles is developed. ${ }^{39} \mathrm{Gu}$ et al. ${ }^{40}$ have fabricated the $\mathrm{Fe}_{3} \mathrm{O}_{4}$ /PANI nanocomposites by surface initiated polymerization (SIP) method, in which the ES form PANI served as the coating layer to protect the $\mathrm{Fe}_{3} \mathrm{O}_{4}$ nanoparticles from the acid dissolution. The prepared $\mathrm{Fe}_{3} \mathrm{O}_{4} / \mathrm{PANI}$ nanocomposites showed a good $\mathrm{Cr}(\mathrm{VI})$ removal performance within the whole $\mathrm{pH}$ range and the presence of $\mathrm{Fe}_{3} \mathrm{O}_{4}$ core favored the recycle of $\mathrm{Fe}_{3} \mathrm{O}_{4} / \mathrm{PANI}$ nanocomposites. After recycling, the $\mathrm{Fe}_{3} \mathrm{O}_{4} / \mathrm{PANI}$ nanocomposites could be easily regenerated by the $1 \mathrm{~mol} \mathrm{~L}^{-1} p$-toluene sulfonic acid (PTSA) solution and reused for $\mathrm{Cr}(\mathrm{VI})$ removal. Meanwhile, they have combined the Fourier transform infrared spectroscopy (FT-IR), X-ray photoelectron spectroscopy (XPS), energy-filtered transmission electron microscopy (EFTEM), inductively coupled plasma optical emission spectrometry (ICP-OES) and temperature dependent resistivity measurements to explore the $\mathrm{Cr}(\mathrm{VI})$ removal mechanism. The results confirmed that the $\mathrm{Cr}(\mathrm{VI})$ removal by the synthesized PANI nanocomposites followed one stage $\mathrm{Cr}(\mathrm{VI})$ reduction by PANI and the reduced $\mathrm{Cr}(\mathrm{III})$ adsorbed in the PANI nanocomposites. The proposed $\mathrm{Cr}(\mathrm{VI})$ removal mechanism is shown in Fig. 2. The detailed PANI and PANI nanocomposites for heavy metal removal please refers to the literature. ${ }^{29,41}$

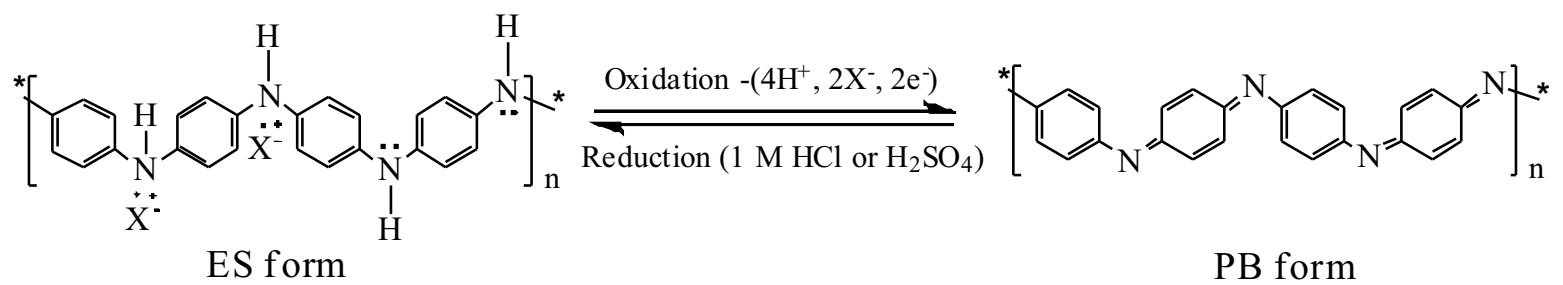

Fig. 1 Conversion of PANI between ES form and PB form.

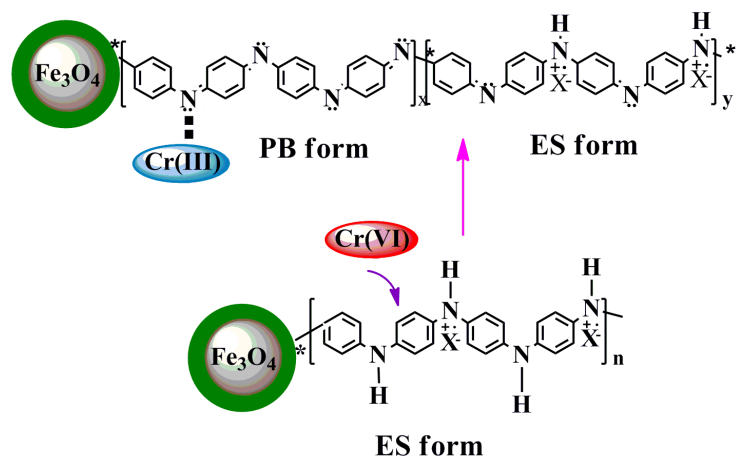

Fig. 2 Proposed mechanism of $\mathrm{Cr}(\mathrm{VI})$ removal by magnetic PANI nanocomposites (X represents doped acid PTSA). Adapted and reduced with the permission from Ref. 40. Copyright 2012, Royal Society of Chemistry. 


\subsection{Giant Magnetoresistance (GMR) Sensors}

Magnetoresistance (MR) is used to describe a resistance change under an applied external magnetic field. The schematic for measurement of MR is shown in Fig. 3. The positive and negative MR respectively mean the increase and decrease in resistance of a material upon the external magnetic field. Since the first report of giant magnetoresistance (GMR) in a multilayered thin-film structural metallic nanocomposites consisting of a couple of ferromagnetic $\mathrm{Fe}$ layers separated by a nonmagnetic Cr layer in 1988 by Drs. Fert and Grünberg's group, ${ }^{42,}{ }^{43}$ much more scientists and engineers start to focus on this topic. ${ }^{44,45}$ Scientists want to explain the knowledge of GMR phenomenon and understand the behind physics in order to design and construct the GMR devices with novel structures. ${ }^{46-52}$ Engineers aim to use GMR based devices in the fields of angular position sensing, hard disc drivers, magnetic field sensors, and magnetic random access memory (MRAM) in computers. ${ }^{16,53-57}$ In the past years, organic magnetoresistance (OMAR), as one type of promising electronics, have received more attentions ${ }^{58}$ due to their light-weight, low-cost, easy processing, chemical stability and biocompatible capability relative to the traditional metal materials. ${ }^{59-62}$ Particularly, the OMAR effect in the conducting polymers has been intensively investigated because of their easy synthesis, low-cost, high conductivity and relatively high GMR signals in comparison with other organic materials. ${ }^{63,64}$

In the past decades, the researchers started to study the GMR effect in PANI systems. In general, it's well-known that the electrical conductivity of PANI is related to its molecular weight, inter-chain separation, oxidation level, ${ }^{65,66}$ crystallinity, molecular arrangement, doping degree and type of dopants. ${ }^{67}$ The electrical conductivity of the doped PANI can be tuned to be 8-11 orders of magnitude (which can reach $10^{-1} \sim 10^{2} \mathrm{~S} \mathrm{~cm}^{-1}$ ) higher than that of the PANI base (around $10^{-9} \mathrm{~S} \mathrm{~cm}^{-1}$ ) by choosing the different dopants. ${ }^{68}$ Lately, Gu et al. ${ }^{6,64,69}$ reported the effects of dopants, oxidants and oxidant doses on the GMR values of pure PANI. Specifically, they found a room temperature GMR value of 53\% in the PTSA doped PANI oxidized by ammonium persulfate (APS). ${ }^{64}$ By utilizing the same oxidant, they found a GMR value of $65.5 \%$ at room temperature in the PANI with phosphoric acid $\left(\mathrm{H}_{3} \mathrm{PO}_{4}\right)$ as dopant. ${ }^{69}$ By contrast, around $5 \%$ MR value at room temperature was attained in the PANI synthesized by hexavalent chromium $(\mathrm{Cr}(\mathrm{VI}))$ as the oxidant. ${ }^{6}$

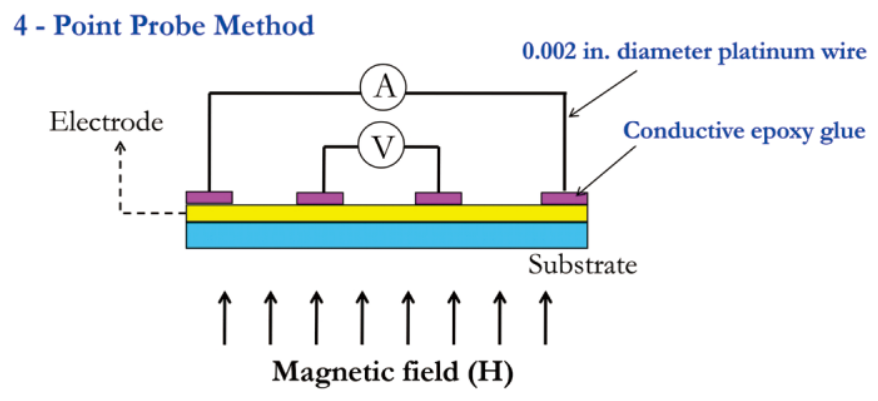

Fig. 3 Schematic for measurement of MR.

Recently, Guo's group has made a breakthrough on the exploring the room temperature GMR effect in the PANI nanocomposites. ${ }^{64,70}$ They have used the surface initiated polymerization (SIP) method to fabricate the PANI nanocomposites with magnetic, insulating and semi-conducting nanofillers, which exhibited the different GMR values in these PANI nanocomposites. For example, around GMR value of $95 \%$ was acquired in the 30 wt $\%$ loading of magnetic $\mathrm{Fe}_{3} \mathrm{O}_{4} / \mathrm{PANI}$ nanocomposites, Fig. $4 \mathrm{a} .{ }^{64} \mathrm{~A}$ GMR value about $95.5 \%$ was found in the $20 \mathrm{wt} \%$ loading of nonmagnetic silica/PANI nanocomposites. ${ }^{69}$ In addition, a GMR value of $20 \%$ was received in the $20 \mathrm{wt} \%$ loading of non-magnetic PANI nanocomposites with a $\mathrm{BaTiO}_{3}(\sim 500 \mathrm{~nm})$ nanoparticles prepared by SIP method, whereas around $35 \%$ value of GMR value was gained in the $20 \mathrm{wt} \%$ loading of $\mathrm{BaTiO}_{3}(\sim 500 \mathrm{~nm}) / \mathrm{PANI}$ nanocomposites prepared by just simple physical mixing PANI with $\mathrm{BaTiO}_{3}$ powders. ${ }^{71}$ A $22 \%$ of GMR value at room temperature in the non-magnetic PANI nanocomposites with a silicon loading of 20.0 $\mathrm{wt} \%$ under magnetic field of $9 \mathrm{~T}$ was observed. ${ }^{72,}{ }^{73}$ In the PANI nanocomposites with different carbon nanostructures, the positive GMR $(15 \sim 30 \%)$ was observed at $290 \mathrm{~K}^{74}$ Owing to the stackinginduced efficient electrical transport at the PANI and graphene interface, the room temperature GMR value obtained in the $5 \mathrm{wt} \%$ loading of graphene/PANI nanocomposites was higher than that of PANI nanocomposites with the same loading of 1D CNTs and carbon nanofibers (CNFs). ${ }^{70}$

The aforementioned PANI and PANI nanocomposites possess the positive GMR value, which implies the resistance of materials is increased after applying external magnetic field. More recently, the negative GMR behaviors have also been found in the PANI nanocomposites. For instance, a negative GMR value around $-2 \%$ was observed in the PANI nanocomposites with a multi-walled carbon nanotubes (MWNTs) loading of 5 and $20 \mathrm{wt} \%$ with $\mathrm{Cr}(\mathrm{VI})$ as oxidant. $^{75}$ A large negative GMR with a value of $-35.76 \%$ was obtained in the $40 \mathrm{wt} \%$ loading of cobalt ferrite $\left(\mathrm{CoFe}_{2} \mathrm{O}_{4}\right) / \mathrm{PANI}$ nanocomposites, Fig. 4b. ${ }^{76}$ The large negative GMR value is remarkably important, which means the external magnetic field could significantly decrease the resistance of PANI nanocomposites and increase their electrical conductivity.

All of these reports suggest that the external magnetic field is able to tune the resistance of PANI and PANI nanocomposites, depending on the preparation method, oxidants, dopants, and type of nanofillers, which allows PANI and its nanocomposites to be used in the GMR sensor applications. The details please see reference. ${ }^{77}$
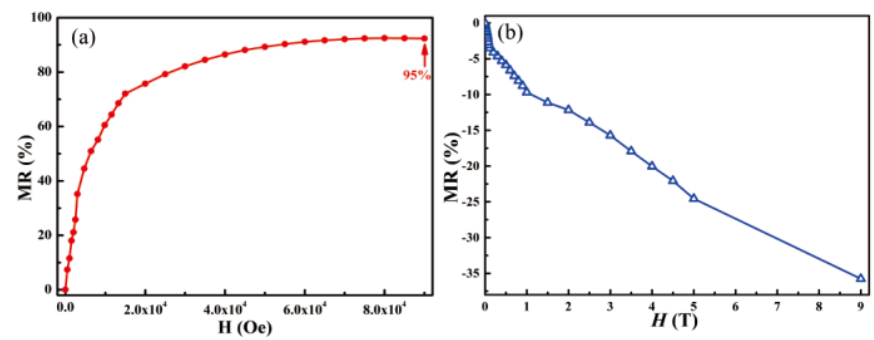

Fig. 4 GMR of (a) $30 \mathrm{wt} \% \mathrm{Fe}_{3} \mathrm{O}_{4}$ loading of PANI nanocomposites at room temperature; (b) $40 \mathrm{wt} \%$ loading of $\mathrm{CoFe}_{2} \mathrm{O}_{4} / \mathrm{PANI}$ nanocomposites. Adapted and reduced with the permission from Ref. 64. Copyright 2012; Ref. 76. Copyright 2018, Elsevier.

\subsection{Coupling Agent}

Epoxy resins are very conventional and important engineered thermosetting polymers because of their high tensile strength, Young's modulus, good thermal and electrical insulating properties, and wide applications such as adhesives, electronics (excellent electrical insulators), marine and aerospace. ${ }^{78}$ The mechanical properties of epoxy could be improved by the introduction of strong fillers and nanofillers through formation of polymer composites and nanocomposites, which could further provide epoxy with unique 
properties including optical, ${ }^{79}$ anticorrosive, ${ }^{80,81}$ magnetic properties, ${ }^{82}$ electrical and thermal conductivity. ${ }^{83-85}$ However, owing to the easy agglomeration and large surface energy at nanoscale level, in order to obtain high performance epoxy nanocomposites, the nanofiller dispersion quality and the interfacial interaction between nanofillers and epoxy matrix are two key factors to be solved. ${ }^{86}$ Generally, surface treatment is a common way to ameliorate the dispersion problem and improve the interfacial interaction through using proper coupling agents, ${ }^{87,88}$ surfactant $^{89}$ and polymers. ${ }^{90}$ Due to the presence of unique amine and imine groups in the backbone, recently, $\mathrm{Gu}$ et $a l^{82,91-96}$ have applied PANI to serve as the coupling agent to improve the nanofiller dispersion and boost the interfacial interaction between nanofillers and epoxy matrix. They have used PANI to tune the surface functionality of magnetite $\left(\mathrm{Fe}_{3} \mathrm{O}_{4}\right)$ nanoparticles through SIP method, $^{82}$ the ultimate tensile strength was increased from $79.3 \mathrm{MPa}$ for $5 \mathrm{wt} \%$ loading of untreated $\mathrm{Fe}_{3} \mathrm{O}_{4}$ /epoxy nanocomposites to 93.1 $\mathrm{MPa}$ for the same loading of PANI functionalized $\mathrm{Fe}_{3} \mathrm{O}_{4} /$ epoxy nanocomposites, Fig. 5. Meanwhile, the prepared PANI functionalized $\mathrm{Fe}_{3} \mathrm{O}_{4}$ /epoxy nanocomposites also exhibited a good magnetic property. They have also prepared a high performance MWNTs reinforced epoxy nanocomposites by surface treatment of
PANI on MWNTs with $\mathrm{Cr}(\mathrm{VI})$ as oxidant, Fig. 6, in which the ultimate tensile strength of $0.7 \mathrm{wt} \%$ loading of PANI modified MWNTs/epoxy nanocomposites was increased by $85 \%$ compared to the pure epoxy. ${ }^{91}$

In addition, they have introduced the flame retardant properties ${ }^{95}$ into epoxy by using PANI as coupling agent. ${ }^{92}$ After adopting the phosphoric acid $\left(\mathrm{H}_{3} \mathrm{PO}_{4}\right)$ doped PANI to coat silica nanoparticles, the prepared silica/PANI/ $\mathrm{H}_{3} \mathrm{PO}_{4} /$ epoxy nanocompoistes displayed an evident decreased heat release rate (HRR) peak compared with other materials including pure epoxy, as-received silica/epoxy, and silica/PANI $/ \mathrm{H}_{2} \mathrm{SO}_{4}$ /epoxy nanocomposites (Generally, the lower HRR peak, the better flame retardant property would be.), Fig. 7A. As confirmed in the morphology after combustion under nitrogen conditions at $700{ }^{\circ} \mathrm{C}$, Fig. $7 \mathrm{~B}$, the silica/PANI/ $\mathrm{H}_{3} \mathrm{PO}_{4} /$ epoxy nanocompoistes depicted a continuous and condensed-phase morphology rather than a smooth and porous structure with many broken bubbles in pure epoxy and silica/PANI/ $\mathrm{H}_{2} \mathrm{SO}_{4} /$ epoxy nanocomposites, further indicating that the flame retardant property of epoxy was also associated with the doped acid of PANI. For the detailed information about multifunctional epoxy nanocomposites, please mention reference. ${ }^{86}$
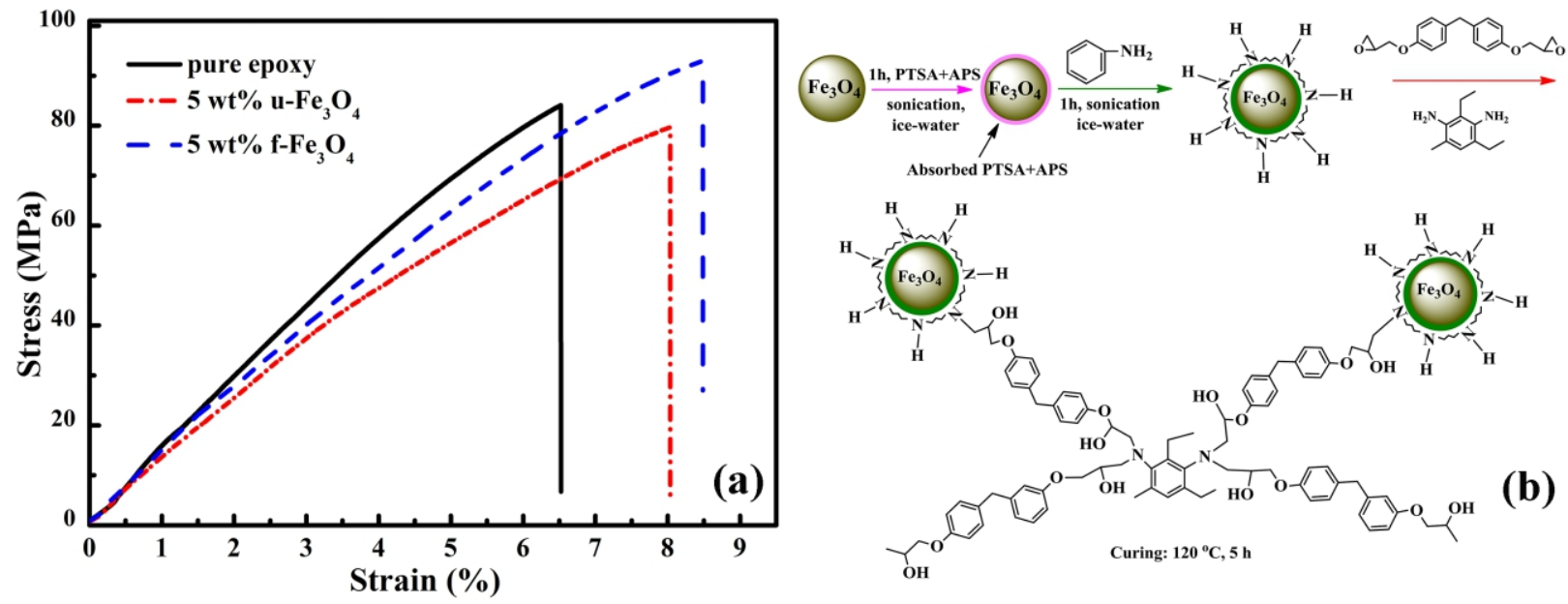

Fig. 5 (a) Stress-strain curve of pure epoxy and $\mathrm{Fe}_{3} \mathrm{O}_{4} /$ epoxy nanocomposites; (b) schematic for curing process of $\mathrm{Fe}_{3} \mathrm{O}_{4} /$ epoxy nanocomposites. Adapted and reduced with the permission from Ref. 82. Copyright 2012, American Chemical Society.
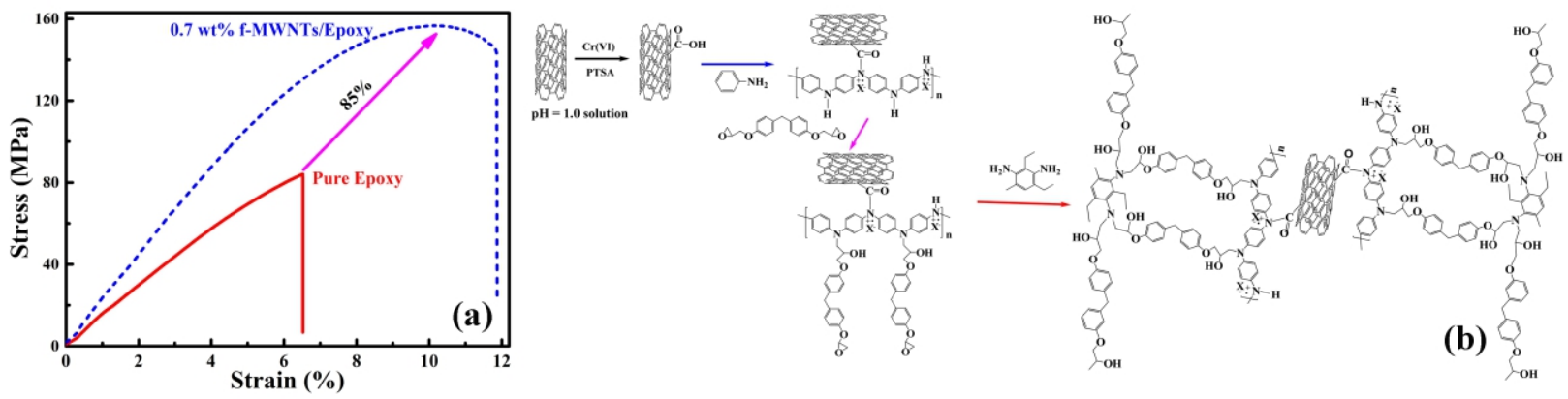

Fig. 6 (a) Stress-strain curve of pure epoxy and MWNTs/epoxy nanocomposites; (b) Schematic for preparation of MWNTs/epoxy nanocomposites. Adapted and reduced with the permission from Ref. 91. Copyright 2013, Royal Society of Chemistry. 

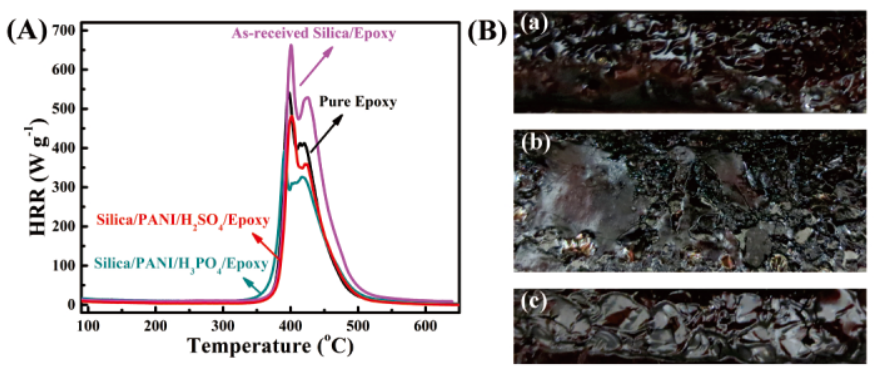

Fig. 7 (A) HRR as a function of temperature for pure epoxy, and epoxy nanocomposites filled with as-received silica and $f$-silica doped with $\mathrm{H}_{3} \mathrm{PO}_{4}, \mathrm{H}_{2} \mathrm{SO}_{4}$; (B) digital photos of (a) pure epoxy, and silica/epoxy nanocomposites filled with $5 \mathrm{wt} \% f$-silica doped with (b) $\mathrm{H}_{3} \mathrm{PO}_{4}$, (c) $\mathrm{H}_{2} \mathrm{SO}_{4}$ after combustion in the nitrogen condition at $700{ }^{\circ} \mathrm{C}$. Adapted and reduced with the permission from Ref. 92. Copyright 2013, American Chemical Society.

\subsection{Metamaterials}

In the last decades, the metamaterials (materials with both negative permittivity and permeability at a given frequency of radiation) have gained more attentions due to their unique negative refractive index for the applications of cloaking, subwavelength imaging and invisibility fields. ${ }^{97}$ Recently, as a non-magnetic material, in which the permeability is $1,{ }^{98}$ the PANI and its nanocomposites have been reported to depict unique negative permittivity, which make PANI and its nanocomposites to be able to serve as metamaterials and metacomposites. ${ }^{99,}{ }^{100}$ This negative permittivity behavior is mainly contributed to the formation of a continuous conductive network in the PANI polymer chain, i.e. electrical conductivity of PANI. Normally, the electrical conductivity of PANI could be tuned by the molecular weight, molecular arrangement, oxidation level, crystallinity, doped acid and doping level, which means that all of these parameters might bring the effect on the permittivity of PANI. For example, $\mathrm{Gu}$ et al. found that the PTSA doped PANI showed a negative permittivity, ${ }^{64}$ whereas $\mathrm{H}_{3} \mathrm{PO}_{4}$ doped PANI exhibited a positive permittivity. ${ }^{69}$

Interestingly, Guo et al. ${ }^{65,75,100}$ have reported a component rather than structure controlled negative permittivity, in which the permittivity of PANI nanocomposites could be tailored by altering the loading and morphologies of nanofillers. As shown in Fig. $8 \mathrm{a},{ }^{75}$ in the MWNTs/PANI nanocomposites, the real permittivity $\left(\varepsilon^{\prime}\right)$ for all of the MWNTs/PANI nanocomposites was negative within the measured frequency range and differs from each other with different loadings of MWNTs. They believed that this phenomenon might be from the fact that the presence of MWNTs was possibly change the charge carrier transport within PANI matrix and further influence the charge delocalization since the permittivity was related to the charge transport and electrical conductivity. In another work, ${ }^{70}$ they discovered that different morphologies of carbon nanostructures could bring the different effects on the negative permittivity arising from the charge delocalization at the interface between carbon nanostructures and PANI matrix. Especially, because of the good interfacial interaction between CNFs or CNTs and PANI matrix, the switching frequency, at which the permittivity was changed from negative to positive, for CNFs or CNTs/PANI nanocomposites was higher than that of graphene/PANI nanocomposites.

Generally, as an important parameter of medium, plasma frequency $\left(\omega_{p}\right)$ is a unique frequency, where the frequency is switched from negative to positive. This implys that when the angular frequnecy $(\omega)$ of the incident light is lower than $\omega_{p}$, medium behaves as a metamaterial; as the $\omega$ is higher than $\omega_{p}$, the material is an ordinary dielectric medium. Therefore, the determination of $\omega_{p}$ is vital to a material. Gu and Guo et al. ${ }^{101}$ have also tried to used Drude model modified by Debye relaxation time to determine the $\omega_{p}$ of $\beta$ silicon carbide (SiC)/PANI nanocomposites. They applied PolyMath software to fit the equation gained from Drude model modified by Debye relaxation time and the obtained results for $10.0 \mathrm{wt} \% \beta$ $\mathrm{SiC} / \mathrm{PANI}$ nanocomposites have been illustrated in Fig. $8 \mathrm{~b}$. With a high fitting coefficient of 0.9969 , they calculated the $\omega_{p}$ for $10.0 \mathrm{wt} \%$ $\beta$-SiC/PANI nanocomposites was $1.5310^{5} \mathrm{rad} \mathrm{s}^{-1}$. Meanwhile, this $\omega_{p}$ also had a nanoparticle loading dependent property and the $\beta$ $\mathrm{SiC} / \mathrm{PANI}$ nanocomposites with different $\beta$-SiC nanoparticle loadings possessed the different $\omega_{p}$. The detailed fundamentals about negative permittivity please look though the reference. ${ }^{21}$
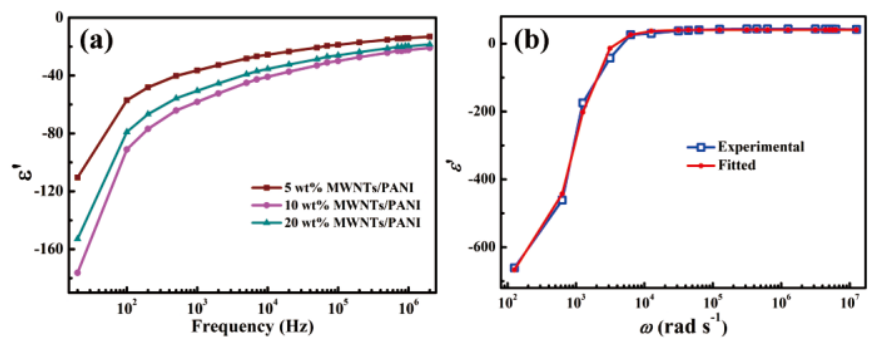

Fig. 8 (a) Real permittivity $\left(\varepsilon^{\prime}\right)$ as a function of frequency for MWNTs/PANI nanocomposites; (b) experimentally measured and calculated $\varepsilon^{\prime}$ as a function of angular frequency for $10.0 \mathrm{wt} \% \beta$ $\mathrm{SiC} / \mathrm{PANI}$ nanocomposites. Adapted and reduced with the permission from Ref. 75. Copyright 2014; Ref. 101. Copyright 2016, Royal Society of Chemistry.

\subsection{Energy Storage Devices}

Owing to the high faradaic activity, fast and reversible redox reaction, low cost, and good electrical conductivity, PANI is well-known used as faradaic supercapacitors or pesudocapacitors for energy storage. ${ }^{102}$ In order to improve its energy storage performance, various nanofillers such as graphene, ${ }^{103} \mathrm{CNTs},{ }^{104} \mathrm{Fe}_{3} \mathrm{O}_{4},{ }^{105} \mathrm{Fe}_{2} \mathrm{O}_{3},{ }^{106}$ and $\mathrm{MoS}_{2}{ }^{107}$ have been utilized to synthesize the PANI nanocomposites. Recently, Wang et $a l^{108}$ prepared a flexible conductive porous electrode (indexed as PANI-ZIF-67-CC) by fabrication of cobalt-based MOF crystals (ZIF67) onto carbon cloth (CC) and further electrically deposited PANI with the purpose of solving the insulating problems of MOFs, which displayed an extraordinary areal capacitance of $2146 \mathrm{mF} \mathrm{cm} \mathrm{ct}^{-2}$ at scanning rate of $10 \mathrm{mV} \mathrm{s}^{-1}$. Heeger et al. ${ }^{109}$ combined the porous electrochemically-active PANI and the electrolyte-an benzoquinonehydroquinone (BQHQ) redox couple to create a tunable redox shuttle which controlled the electron transfer processes at the PANI modifiedelectrodes, which provided the electrodes a high pseudocapacitance and cycling stability $(>50,000)$.

As aforementioned in the introduction, normally, PANI has three different states designated as LEB (completely reduced state), EB (half-oxidized state), and PB (fully oxidized state) forms. ${ }^{110}$ Owing to the different colors of these three states, PANI can be exploited in the electrochromic devices such as smart windows and displays. ${ }^{111}$ Wei et $a l^{10,}, 112$ have linked this electrochromic behavior with electrochemical energy storage and made a comprehensive study on this regard in the 

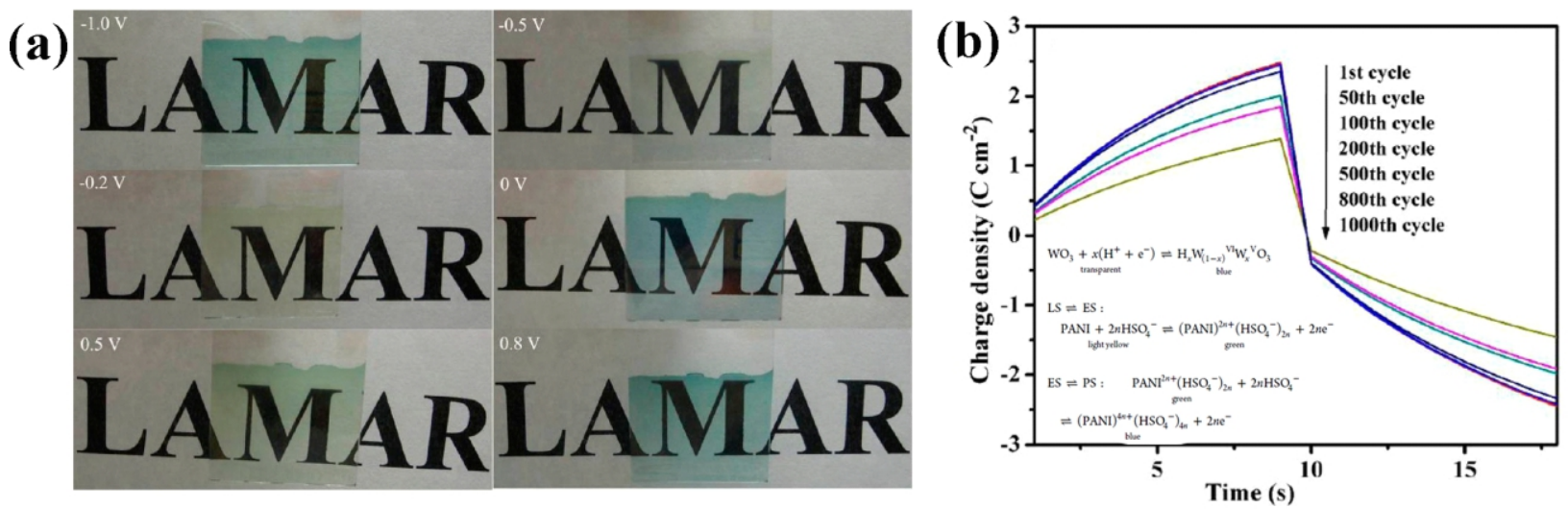

Fig. 9 (a) Color switching illustration of PANI/WO $/ \mathrm{WO}_{3}$ composite film in $0.5 \mathrm{M} \mathrm{H}_{2} \mathrm{SO}_{4}$ at different potentials; (b) $\mathrm{PANI} / \mathrm{WO} \mathrm{O}_{3}$ composite film in 0.5 $\mathrm{M} \mathrm{H}_{2} \mathrm{SO}_{4}$ aqueous solution with the potential step of 0.8 and $-0.2 \mathrm{~V}$ holding for $10 \mathrm{~s}$. Adapted and reduced with the permission from Ref. 112 . Copyright 2012, American Chemical Society.
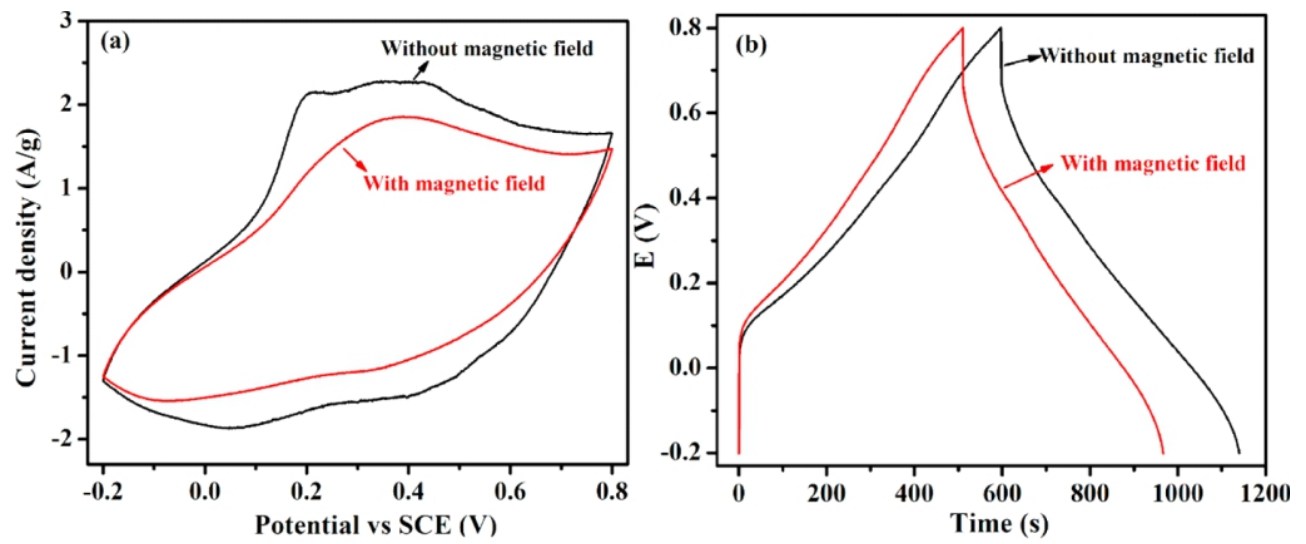

Fig. 10 (a) $\mathrm{CV}$ curve at a scan rate of $5 \mathrm{mV} \mathrm{s}^{-1}$, (b) the charge-discharge plot at a current density of $1 \mathrm{~A} \mathrm{~g}^{-1}$ for silica/PANI nanocomposites. Adapted and reduced with the permission from Ref. 66. Copyright 2013, American Chemical Society.

tungsten oxide $\left(\mathrm{WO}_{3}\right) / \mathrm{PANI}$ nanocomposites and graphite/PANI nanocomposites. Taking $\mathrm{WO}_{3} / \mathrm{PANI}$ nanocomposites as an example, Fig. 9a, the $\mathrm{WO}_{3}$ /PANI nanocomposite film illustrated a multiple colors with the CV scanning from -1.0 to $0.8 \mathrm{~V}$. The nanocomposite film was blue at potential of $0.8 \mathrm{~V}$ to green at $0.5 \mathrm{~V}$ during the positive sweeping, and then turned to the light yellow at $-0.2 \mathrm{~V}$, light blue at $0.5 \mathrm{~V}$, and blue at $-1.0 \mathrm{~V}$ in the negative sweeping. The corresponding protonation/deprotonation of $\mathrm{H}^{+}$in the $\mathrm{WO}_{3} / \mathrm{PANI}$ nanocomposite film for this color switching during the $\mathrm{CV}$ scanning is shown in inset of Fig. 9b. Meanwhile, the $\mathrm{WO}_{3} / \mathrm{PANI}$ nanocomposite film exhibited areal capacitance at a broad working potential window with a much more enhanced durability during the charge-discharge cycles (Fig. 9b) comparable to that of the PANI film due to the chemical interaction between PANI matrix and $\mathrm{WO}_{3}$ nanoparticles.

More recently, Guo's group has made a great progress on a magnetic field induced capacitance enhancement (called magnetocapacitance). ${ }^{113,114}$ They have only employed a low magnetic field of $0.072 \mathrm{~T}$ on the capacitors, the energy densities were dramatically increased..$^{115}$ They have also tried this strategy on the PANI and PANI nanocomposites. ${ }^{6,66}$ As shown in $\mathrm{CV}$ curves and charge-discharge process at a current density of $1 \mathrm{~A} \mathrm{~g}^{-1}$ with/without magnetic field at $5 \mathrm{mV} \mathrm{s}^{-1}$, Fig. 10, they found that the capacitance was obviously declined after applying external magnetic field, meaning that the magnetic field was not favorable for the electrochemical performance. They believed that this phenomenon might be arose from a positive GMR (increased resistance with response to the external magnetic field) in the silica/PANI nanocomposites under the external magnetic field and the increased transport path length of the charge carrier because of Lorentz force under an external magnetic field.

\section{Conclusions}

In this paper, the state-of-art current research status on the recent developed new functions of conducting polymer PANI in the applications such as environmental remediation, GMR sensors, coupling agent for epoxy and nanofillers, metamaterials, and energy storage have been critically reviewed. This knowledge is aiming to give a fundamental for further broadening the application scope of PANI and provide a basis for researchers to seek the new application of PANI in the future by optimizing the excellent and tunable electrical conductivity as well as unique chemical structures of PANI and its nanocomposites.

\section{Acknowledgements}

This work is supported by Shanghai Science and Technology Commission (14DZ2261100) and Space Supporting Fund from 
China Aerospace Science and Industry Corporation (2018-HT-XG). The authors are grateful for the support and funding from the Foundation of National Natural Science Foundation of China (Nos. 51703165), Foundation of Aeronautics Science Fund (2017ZF53071), and Young Elite Scientist Sponsorship Program by CAST (YESS, No. 2016QNRC001). This project is supported by special fund of State Key Joint Laboratory of Environment Simulation and Pollution Control (17K02ESPCT).

\section{References}

1. H. Shirakawa, E. J. Louis, A. G. MacDiarmid, C. K. Chiang and A. J. Heeger, J. Chem. Soc., Chem. Commun., 1977, 578-580.

2. R. Green and M. R. Abidian, Adv. Mater., 2015, 27, 7620-7637.

3. H. Wei, X. Yan, Y. Li, H. Gu, S. Wu, K. Ding, S. Wei and Z. Guo, J. Phys. Chem. C, 2012, 116, 16286-16293.

4. J. Stejskal and R. G. Gilbert, Pure Appl. Chem., 2002, 74, 857867.

5. X. Zhang, J. Zhu, N. Haldolaarachchige, J. Ryu, D. P. Young, S. Wei and Z. Guo, Polymer, 2012, 53, 2109-2120.

6. H. Gu, H. Wei, J. Guo, N. Haldolaarachige, D. P. Young, S. Wei and Z. Guo, Polymer, 2013, 54, 5974-5985.

7. J. Zhu, M. Chen, H. Qu, X. Zhang, H. Wei, Z. Luo, H. A. Colorado, S. Wei and Z. Guo, Polymer, 2012, 53, 5953-5964.

8. H. Wei, H. Gu, J. Guo, S. Wei and Z. Guo, J. Electrochem. Soc., 2013, 160, G3038-G3045.

9. H. Qu, S. Wei and Z. Guo, J. Mater. Chem. A, 2013, 1, 1151311528.

10. H. Wei, J. Zhu, S. Wu, S. Wei and Z. Guo, Polymer, 2013, 54, 1820-1831.

11. C. Belabed, A. Abdi, Z. Benabdelghani, G. Rekhila, A. Etxeberria and M. Trari, Int. J. Hydrogen Energy, 2013, 38, 6593-6599.

12. J. Gong, Y. Li, Z. Hu, Z. Zhou and Y. Deng, J. Phys. Chem. C, 2010, 114, 9970-9974.

13. J. J. Alcaraz-Espinoza, A. E. Chávez-Guajardo, J. C. MedinaLlamas, C. A. S. Andrade and C. P. de Melo, ACS Appl. Mater. Interfaces, 2015, 7, 7231-7240.

14. M. K. Kim, K. Shanmuga Sundaram, G. Anantha Iyengar and K.-P. Lee, Chem. Eng. J., 2015, 267, 51-64.

15. G. Sharma, D. Pathania, M. Naushad and N. C. Kothiyal, Chem. Eng. J. 2014, 251, 413-421.

16. H. Gu, X. Zhang, H. Wei, Y. Huang, S. Wei and Z. Guo, Chem. Soc. Rev., 2013, 5907-5943.

17. A. G. MacDiarmid, S. K. Manohar, J. G. Masters, Y. Sun, H. Weiss and A. J. Epstein, Synth. Met., 1991, 41, 621-626.

18. T. Ogoshi, Y. Hasegawa, T. Aoki, Y. Ishimori, S. Inagi and T.-a. Yamagishi, Macromolecules, 2011, 44, 7639-7644.

19. R. J. Mortimer, Chem. Soc. Rev., 1997, 26, 147-156.

20. S. Bhadra, D. Khastgir, N. K. Singha and J. H. Lee, Prog. Polym. Sci., 2009, 34, 783-810.

21. H. Gu, J. Guo, S. Wei and Z. Guo, J. Appl. Polym. Sci., 2013, 130, 2238-2244.

22. A. Al-Ahmed, H. M. Bahaidarah and M. A. J. Mazumder, $A d v$. Mater. Res., 2013, 810, 173-216.

23. M. Sairam, S. Nataraj, T. M. Aminabhavi, S. Roy and C. Madhusoodana, Sep. Purif. Rev., 2006, 35, 249-283.

24. C. O. Baker, X. Huang, W. Nelson and R. B. Kaner, Chem. Soc. Rev., 2017, 46, 1510-1525.

25. B. Xiang, D. Ling, H. Lou and H. Gu, J. Hazard. Mater., 2017, 325, 178-188.

26. F. Fu and Q. Wang, J. Environ. Manage., 2011, 92, 407-418.
27. X. Xu, H. Zhang, C. Ma, H. Gu, H. Lou, S. Lyu, C. Liang, J. Kong and J. Gu, J. Hazard. Mater., 2018, 353, 166-172.

28. H. Gu, X. Xu, H. Zhang, C. Liang, H. Lou, C. Ma, Y. Li, Z. Guo and J. Gu, Eng. Sci., 2018, 1, 46-54.

29. E. N. Zare, A. Motahari and M. Sillanpää, Environ. Res., 2018, 162, 173-195.

30. M. Sankir, S. Bozkir and B. Aran, Desalination, 2010, 251, 131136.

31. R. Karthik and S. Meenakshi, Chem. Eng. J., 2015, 263, 168177.

32. J. Wang, B. Deng, H. Chen, X. Wang and J. Zheng, Environ. Sci. Technol., 2009, 43, 5223-5228.

33. P. A. Kumar, S. Chakraborty and M. Ray, Chem. Eng. J., 2008, 141, 130-140.

34. R. Zhang, H. Ma and B. Wang, Ind. Eng. Chem. Res., 2010, 49, 9998-10004.

35. A. Olad and R. Nabavi, J. Hazard. Mater., 2007, 147, 845-851.

36. R. Senthurchelvan, Y. Wang, S. Basak and K. Rajeshwar, J. Electrochem. Soc., 1996, 143, 44-51.

37. J. Huang and R. B. Kaner, Chem. Commun., 2006, 367-376.

38. X. Guo, G. T. Fei, H. Su and D. Z. Li, J. Phys. Chem. C, 2011, 115, 1608-1613.

39. A. E. Chávez-Guajardo, J. C. Medina-Llamas, L. Maqueira, C. A. S. Andrade, K. G. B. Alves and C. P. de Melo, Chem. Eng. J., 2015, 281, 826-836.

40. H. Gu, S. Rapole, J. Sharma, Y. Huang, D. Cao, H. A. Colorado, Z. Luo, N. Haldolaarachchige, D. P. Young, S. Wei and Z. Guo, RSC Advances, 2012, 2, 11007-11018.

41. B. Qiu, C. Xu, D. Sun, Q. Wang, H. Gu, X. Zhang, B. L. Weeks, J. Hopper, T. C. Ho, Z. Guo and S. Wei, Appl. Surf. Sci., 2015, 334, 7-14.

42. M. N. Baibich, J. M. Broto, A. Fert, F. N. Van Dau, F. Petroff, P. Etienne, G. Creuzet, A. Friederich and J. Chazelas, Phys. Rev. Lett., 1988, 61, 2472.

43. G. Binasch, P. Grünberg, F. Saurenbach and W. Zinn, Phys. Rev. $B, 1989$, 39, 4828-4830.

44. A. Fert, Angew. Chem. Int. Ed., 2008, 47, 5956-5967.

45. P. A. Grünberg, Rev. Mod. Phys., 2008, 80, 1531-1540.

46. F. L. Bloom, W. Wagemans, M. Kemerink and B. Koopmans, Phys. Rev. Lett., 2007, 99, 257201.

47. Z. Guo, S. Park, H. T. Hahn, S. Wei, M. Moldovan, A. B. Karki and D. P. Young, Appl. Phys. Lett., 2007, 90, 05311.

48. Z. Guo, H. T. Hahn, H. Lin, A. B. Karki and D. P. Young, J. Appl. Phys., 2008, 104, 014314.

49. Z. Guo, M. Moldovan, D. P. Young, L. L. Henry and E. J. Podlaha, Electrochem. Solid State Lett., 2007, 10, E31-E35.

50. D. Zhang, R. Chung, A. B. Karki, F. Li, D. P. Young and Z. Guo, J. Phys. Chem. C, 2009, 114, 212-219.

51. J. Zhu, S. Wei, N. Haldolaarachchige, J. He, D. P. Young and Z. Guo, Nanoscale, 2012, 4, 152-156.

52. J. Zhu, Z. Luo, S. Wu, N. Haldolaarachchige, D. P. Young, S. Wei and Z. Guo, J. Mater. Chem., 2012, 22, 835-844.

53. G. D. Prasanna, H. S. Jayanna and V. Prasad, J. Appl. Polym. Sci., 2011, 120, 2856-2862.

54. B. Srinivasan, Y. Li, Y. Jing, Y. Xu, X. Yao, C. Xing and J.-P. Wang, Angew. Chem. Int. Ed., 2009, 48, 2764-2767.

55. J. Guo, H. Gu, H. Wei, Q. Zhang, N. S. Haldolaarachchige, Y. Li, D. P. Young, S. Wei and Z. Guo, J. Phys. Chem. C, 2013, 117, 10191-10202.

56. R. S. Gaster, L. Xu, S.-J. Han, R. J. Wilson, D. A. Hall, S. J. Osterfeld, H. Yu and S. X. Wang, Nat Nano, 2011, 6, 314-320. 
57. D. A. Hall, R. S. Gaster, T. Lin, S. J. Osterfeld, S. Han, B. Murmann and S. X. Wang, Biosens. Bioelectron., 2010, 25, 2051-2057.

58. L. Bogani and W. Wernsdorfer, Nat Mater, 2008, 7, 179-186.

59. M. Irimia-Vladu, N. S. Sariciftci and S. Bauer, J. Mater. Chem., 2011, 21, 1350-1361.

60. P. A. Bobbert, T. D. Nguyen, F. W. A. van Oost, B. Koopmans and M. Wohlgenannt, Phys. Rev. Lett., 2007, 99, 216801.

61. J. J. H. M. Schoonus, P. G. E. Lumens, W. Wagemans, J. T. Kohlhepp, P. A. Bobbert, H. J. M. Swagten and B. Koopmans, Phys. Rev. Lett., 2009, 103, 146601.

62. W. Wagemans, A. J. Schellekens, M. Kemper, F. L. Bloom, P. A. Bobbert and B. Koopmans, Phys. Rev. Lett., 2011, 106, 196802.

63. Z. H. Xiong, D. Wu, Z. Valy Vardeny and J. Shi, Nature, 2004, 427, 821-824.

64. H. Gu, Y. Huang, X. Zhang, Q. Wang, J. Zhu, L. Shao, N. Haldolaarachchige, D. P. Young, S. Wei and Z. Guo, Polymer, 2012, 53, 801-809.

65. J. Zhu, S. Wei, L. Zhang, Y. Mao, J. Ryu, N. Haldolaarachige, D. P. Young and Z. Guo, J. Mater. Chem., 2011, 21, 3952-3959.

66. H. Wei, H. Gu, J. Guo, S. Wei, J. Liu and Z. Guo, J. Phys. Chem. C, 2013, 117, 13000-13010.

67. J. E. Yoo, T. L. Bucholz, S. Jung and Y.-L. Loo, J. Mater. Chem., 2008, 18, 3129-3135.

68. J. Stejskal, I. Sapurina, M. Trchová, J. Prokeš, I. Křivka and E. Tobolková, Macromolecules, 1998, 31, 2218-2222.

69. H. Gu, J. Guo, X. Zhang, Q. He, Y. Huang, H. A. Colorado, N. S. Haldolaarachchige, H. L. Xin, D. P. Young, S. Wei and Z. Guo, J. Phys. Chem. C, 2013, 117, 6426-6436.

70. J. Zhu, H. Gu, Z. Luo, N. Haldolaarachige, D. P. Young, S. Wei and Z. Guo, Langmuir, 2012, 28, 10246-10255.

71. X. Zhang, S. Wei, N. Haldolaarachchige, H. A. Colorado, Z. Luo, D. P. Young and Z. Guo, J. Phys. Chem. C, 2012, 116, 1573115740.

72. H. Gu, J. Guo, H. We, Y. Huang, C. Zhao, Y. Li, Q. Wu, N. Haldolaarachchige, D. P. Young, S. Wei and Z. Guo, Phys. Chem. Chem. Phys., 2013, 15, 10866-10875.

73. H. Gu, J. Guo, R. Sadu, Y. Huang, N. Haldolaarachchige, D. Chen, D. P. Young, S. Wei and Z. Guo, Appl. Phys. Lett., 2013, 102, 212403.

74. U. Sivan, O. Entin-Wohlman and Y. Imry, Phys. Rev. Lett., 1988, 60, 1566-1569.

75. H. Gu, J. Guo, Q. He, Y. Jiang, Y. Huang, N. Haldolaarachige, Z. Luo, D. P. Young, S. Wei and Z. Guo, Nanoscale, 2014, 6, 181189.

76. H. Gu, H. Zhang, J. Lin, Q. Shao, D. P. Young, L. Sun, T. D. Shen and Z. Guo, Polymer, 2018, 143, 324-330.

77. H. Gu, J. Guo, X. Yan, H. Wei, X. Zhang, J. Liu, Y. Huang, S. Wei and Z. Guo, Polymer, 2014, 55, 4405-4419.

78. C. Liang, P. Song, H. Gu, C. Ma, Y. Guo, H. Zhang, X. Xu, Q. Zhang and J. Gu, Composites Part A, 2017, 102, 126-136.

79. H. Gu, C. Ma, C. Liang, X. Meng, J. Gu and Z. Guo, J. Mater. Chem. C, 2017, 5, 4275-4285.

80. R. Yan, Y. Liu, B. Liu, Y. Zhang, Q. Zhao, Z. Sun, W. Hu and N. Zhang, Compos. Commun., 2018, 10, 52-56.

81. N. K. Rawat, S. Ahmad and P. K. Panda, Compos. Commun., 2018, 9, 81-85.

82. H. Gu, S. Tadakamalla, Y. Huang, H. A. Colorado, Z. Luo, N. Haldolaarachchige, D. P. Young, S. Wei and Z. Guo, ACS Appl. Mater. Interfaces, 2012, 4, 5613-5624.
83. Q. Wang and D. S. Su, Compos. Commun., 2018, 9, 54-57.

84. X. Yang, Y. Guo, X. Luo, N. Zheng, T. Ma, J. Tan, C. Li, Q. Zhang and J. Gu, Compos. Sci. Technol., 2018, 164, 59-64.

85. X. Xinzhao, L. Guoming, L. Dongyan, S. Guoxin and Y. Rui, Compos. Commun., 2018, 7, 1-6.

86. H. Gu, C. Ma, J. Gu, J. Guo, X. Yan, J. Huang, Q. Zhang and Z. Guo, J. Mater. Chem. C, 2016, 4, 5890-5906.

87. Z. Guo, T. Pereira, O. Choi, Y. Wang and H. T. Hahn, J. Mater. Chem., 2006, 16, 2800-2808.

88. Z. Guo, S. Wei, B. Shedd, R. Scaffaro, T. Pereira and H. T. Hahn, J. Mater. Chem., 2007, 17, 806-813.

89. Z. Emami, Q. Meng, G. Pircheraghi and I. Manas-Zloczower, Cellulose, 2015, 22, 3161-3176.

90. Y. Kang and T. A. Taton, J. Am. Chem. Soc., 2003, 125, 56505651.

91. H. Gu, S. Tadakamalla, X. Zhang, Y.-D. Huang, Y. Jiang, H. A. Colorado, Z. Luo, S. Wei and Z. Guo, J. Mater. Chem. C, 2013, 1, 729-743.

92. H. Gu, J. Guo, Q. He, S. Tadakamalla, X. Zhang, X. Yan, Y. Huang, H. A. Colorado, S. Wei and Z. Guo, Ind. Eng. Chem. Res., 2013, 52, 7718-7728.

93. H. Gu, J. Guo, H. Wei, X. Yan, D. Ding, X. Zhang, Q. He, S. Tadakamalla, X. Wang, T. C. Ho, S. Wei and Z. Guo, J. Mater. Chem. C, 2015, 3, 8152-8165.

94. H. Gu, H. Zhang, C. Ma, S. Lyu, F. Yao, C. Liang, X. Yang, J. Guo, Z. Guo and J. Gu, J. Phys. Chem. C, 2017, 121, 1326513273.

95. X. Zhang, Q. He, H. Gu, H. A. Colorado, S. Wei and Z. Guo, ACS Appl. Mater. Interfaces, 2012, 5, 898-910.

96. X. Zhang, Q. He, H. Gu, S. Wei and Z. Guo, J. Mater. Chem. C, 2013, 1, 2886-2899.

97. K. Sun, R. Fan, X. Zhang, Z. Zhang, Z. Shi, N. Wang, P. Xie, Z. Wang, G. Fan, H. Liu, C. Liu, T. Li, C. Yan and Z. Guo, J. Mater. Chem. C, 2018, 6, 2925-2943.

98. V. A. Podolskiy and E. E. Narimanov, Phys. Rev. B, 2005, 71, 201101.

99. J. Zhu, S. Wei, L. Zhang, Y. Mao, J. Ryu, P. Mavinakuli, A. B. Karki, D. P. Young and Z. Guo, J. Phys. Chem. C, 2010, 114, 16335-16342.

100. J. Zhu, S. Wei, L. Zhang, Y. Mao, J. Ryu, A. B. Karki, D. P. Young and Z. Guo, J. Mater. Chem., 2011, 21, 342-348.

101. H. Gu, J. Guo, M. A. Khan, D. P. Young, T. D. Shen, S. Wei and Z. Guo, Phys. Chem. Chem. Phys., 2016, 18, 19536-19543.

102. G. Wang, L. Zhang and J. Zhang, Chem. Soc. Rev., 2012, 41, 797-828.

103. W. Chen, R. B. Rakhi and H. N. Alshareef, Nanoscale, 2013, 5, 4134-4138.

104. K. Wang, Q. Meng, Y. Zhang, Z. Wei and M. Miao, Adv. Mater., 2013, 25, 1494-1498.

105. J. Li, W. Lu, Y. Yan and T.-W. Chou, J. Mater. Chem.A, 2017, 5, 11271-11277.

106. X.-F. Lu, X.-Y. Chen, W. Zhou, Y.-X. Tong and G.-R. Li, ACS Appl. Mater. Interfaces, 2015, 7, 14843-14850.

107. L. Ren, G. Zhang, Z. Yan, L. Kang, H. Xu, F. Shi, Z. Lei and Z.-H. Liu, ACS Appl. Mater. Interfaces, 2015, 7, 28294-28302.

108. L. Wang, X. Feng, L. Ren, Q. Piao, J. Zhong, Y. Wang, H. Li, Y. Chen and B. Wang, J. Am. Chem. Soc., 2015, 137, 4920-4923.

109. D. Vonlanthen, P. Lazarev, K. A. See, F. Wudl, A. J. Heeger, Adv. Mater., 2014, 26, 5095-5100.

110. H. Gu, C. Liu, J. Zhu, J. Gu, E. K. Wujcik, L. Shao, N. Wang, 
H. Wei, R. Scaffaro, J. Zhang and Z. Guo, Adv. Compos. Hybrid Mater., 2018, 1, 1-5.

111.H. Gu, D. Cao, J. Kong, J. Gu, Q. Jiang, Y. Li, B. Wang, X. Yan, Y. Chen, J. E. Ryu, M. Hu, Y. Yan, Z. Guo, and D. P. Young, Eng. Sci., 2018, 1, 1-3.

112. H. Wei, X. Yan, S. Wu, Z. Luo, S. Wei and Z. Guo, J. Phys. Chem. C, 2012, 116, 25052-25064.
113. J. Zhu, M. Chen, H. Wei, N. Yerra, N. Haldolaarachchige, Z. Luo, D. P. Young, T. C. Ho, S. Wei and Z. Guo, Nano Energy, 2014, 6, 180-192.

114. J. Zhu, M. Chen, H. Qu, Z. Luo, S. Wu, H. A. Colorado, S. Wei and Z. Guo, Energy Environ. Sci., 2013, 6, 194-204.

115. H. Wei, H. Gu, J. Guo, D. Cui, X. Yan, J. Liu, D. Cao, X. Wang, S. Wei and Z. Guo, Adv. Compos. Hybrid Mater., 2018, 1, 127-134. 